\title{
Westphal Variant of Huntington's Disease
}

\author{
J. E. Cote-Orozco ${ }^{1} \quad$ L. Cabarcas-Castro ${ }^{2} \quad$ J. L. Ramón-Gómez ${ }^{2} \quad$ A. M. Zarante-Bahamón ${ }^{3}$ \\ O. Bernal-Pacheco ${ }^{4}$ E. Espinosa-García ${ }^{1}$
}

${ }^{1}$ Department of Pediatric Neurology, Instituto de Ortopedia Infantil Roosevelt, Universidad Militar Nueva Granada, Bogotá, Colombia

Address for correspondence J. E. Cote-Orozco, MD, Department of

2 Department of Pediatric Neurology, Instituto de Ortopedia Infantil Pediatric Neurology, Faculty of Medicine, Instituto de Ortopedia Infantil Roosevelt, Universidad Militar Nueva Granada, Roosevelt, Bogotá, Colombia

${ }^{3}$ Department of Clinical Genetics, Instituto de Ortopedia Infantil Transversal $3 \mathrm{~N}^{\circ} .49-00$, Bogotá D.C., Colombia Roosevelt, Bogotá, Colombia (e-mail: je.coteorozco@gmail.com).

${ }^{4}$ Division of Movement Disorders, Instituto de Ortopedia Infantil Roosevelt, Hospital Militar Central, Bogotá, Colombia

J Pediatr Neurol 2019;17:28-30.

\begin{abstract}
Keywords

- juvenile Huntington's disease

- HTT gene

- CAG repeat expansion

A Westphal variant of Huntington's disease (HD) is an infrequent presentation of this inherited neurodegenerative disorder. Here, we describe a 14-year-old girl who developed symptoms at the age of 7, with molecular evidence of abnormally expanded CytosineAdenine-Guanine (CAG) repeats in exon 1 of the Huntingtin gene. We briefly review the classical features of this variant highlighting the importance of suspecting HD in a child with parkinsonism and a family history of movement disorder or dementia.
\end{abstract}

\section{Introduction}

Huntington disease (HD) is an autosomal dominant progressive disease caused by a Cytosine-Adenine-Guanine (CAG) repeat expansion in the huntingtin (HTT) gene, characterized by the triad of choreic abnormal movements, cognitive decline, and psychiatric disturbances such as depression. ${ }^{1}$ The juvenile variant of HD (JHD), with onset $\leq 20$ years, accounts from 4.81 to $9.95 \%$ of all cases of HD and only approximately $20 \%$ of JHD have childhood-onset HD with onset of symptoms before 10 years of age (Westphal variant, W-HD). ${ }^{2}$ This clinical triad is also observed in JHD but with a different clinical presentation, with bradykinesia, dystonia, and parkinsonian features being predominant over chorea, associated to neuropsychiatric manifestations and myoclonus and epilepsy in nearly half of patients with JHD. ${ }^{3}$

\section{Case Report}

A 14-year-old girl was referred to our neuropediatric clinic because of a 7-year history of frequent falls by progressive postural instability. During the past 2 years, she developed clumsiness, limb stiffness, dysarthria, hearing impairment,

marked emotional lability with periods of agitation and anxiety, and rapidly declining school performance.

Her early developmental milestones and cognitive function were normal. Her father suffered from a progressive neurological disorder, characterized by chorea and dementia at the age of 45 , and her paternal grandmother, uncles, aunts, and a cousin presented a similar clinical picture (-Fig. 1).

General examination was otherwise normal. Neurologic examination showed slurred speech, abstraction, and calculation impairment; assessment of cranial nerves was unremarkable. We found generalized hyperreflexia and hypertonia, cogwheel rigidity, marked left hemibody dystonic posture with gait limitation and bradykinesia. Sensory examination was unremarkable. No ataxia was observed.

Brain magnetic resonance imaging (MRI) showed bilaterally caudate and putamen atrophy (-Fig. 2). Routine blood tests were normal. Molecular analysis of HTT showed an abnormally expanded 79 CAG repeats allele in exon 1 consistent with a molecular diagnosis of HD.

Tetrabenazine was started at $12.5 \mathrm{mg} / \mathrm{d}$ and increased up to $100 \mathrm{mg} / \mathrm{d}$ with a slight improvement of abnormal dystonic

Copyright (c) 2019 by Georg Thieme Verlag KG, Stuttgart · New York
DOI https://doi.org/ 10.1055/s-0037-1608688. ISSN 1304-2580. 


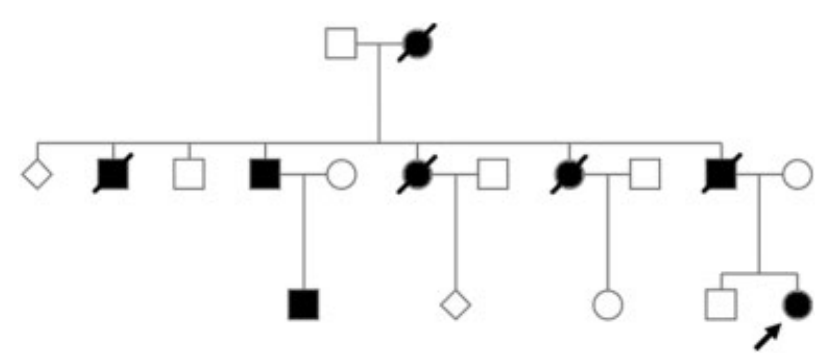

Fig. 1 Family pedigree. Filled boxes indicate symptomatic participants. Arrow points to the proband object of this report.

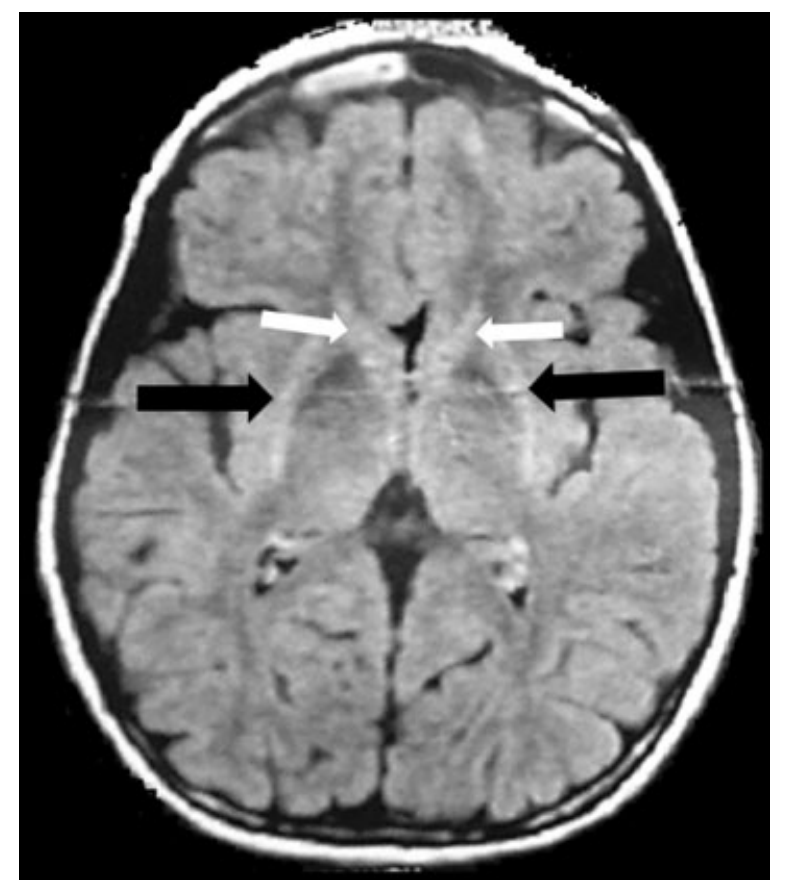

Fig. 2 Axial T2-weighted FLAIR image showing bilateral putaminal hyperintensities (black arrows) and atrophy of the head of caudate nuclei (white arrows). FLAIR, fluid attenuation inversion recovery.

posture and dysarthria. Genetic counseling was given to the family for prenatal guidance.

\section{Discussion}

The described patient had dystonia, gait impairment, rigidity, and neuropsychiatric symptoms that started at the age of 7 years, which is characteristic of the W-HD. This form differs from that in adults, as it has prominent parkinsonism features. ${ }^{4}$ It is proposed that these clinical manifestations are the result of a degeneration of the direct inhibitory striatopallidal projection, which results in increased inhibition of the ventrolateral thalamus. ${ }^{5}$ In the largest study to date, only seven children (1.92\%) had onset of symptoms before the age of 10 years. ${ }^{1}$

Molecular analysis in our patient showed an abnormally expanded 79 CAG repeats in HTT. Patients with early age onset carry large CAG expansions on the HD gene ${ }^{6}$ and most of them, as well as other CAG expansion diseases, show anticipation when the disease is inherited from their father. ${ }^{7}$ An inverse correlation has been described between the number of CAG repeats and the age of onset of $\mathrm{HD},{ }^{8}$ with patients with JHD carrying usually over 60 repeats. There is also a direct correlation between the CAG repeats and the rate of motor and cognitive progression. ${ }^{9}$ Thus, W-HD shows more similarities with an advanced form of adult-onset HD, although other modifier genes might alter the phenotype. ${ }^{10}$

As a predictive test, genetic testing should not be done if the child presents neuropsychiatric symptoms suggestive of $\mathrm{HD}$ and the responsible health professional is concerned about the information being harmful to the patient. ${ }^{11}$ Presymptomatic testing is not indicated in children unless there is a clinical intervention appropriate in childhood; thus, parents should defer knowing their child's genotype. ${ }^{12}$ In $\mathrm{HD}$, an early diagnosis or detection will not give a cure nor will it improve the prognosis. Furthermore, testing positive for HD can generate social stigma, insurance discrimination, and affect patients' development. ${ }^{13}$

Treatment is essentially supportive. Tetrabenazine has been approved by the United States Food and Drug Administration for chorea, but its effect in W-HD is limited. Haloperidol or risperidone have been helpful for behavioral problems, and antidepressants of mood stabilizing medications have been used for neuropsychiatric manifestations. Physical, speech, and occupational therapies are important for maximizing functionality, particularly as the disease progresses. ${ }^{4,5}$

Even though infrequent, W-HD should be suspected when parkinsonism and cognitive decline present in a child with family history of movement disorder and dementia.

Conflict of Interest

None declared.

\section{References}

1 Rasmussen A, Macias R, Yescas P, Ochoa A, Davila G, Alonso E. Huntington disease in children: genotype-phenotype correlation. Neuropediatrics 2000;31(04):190-194

2 Quarrell O, O'Donovan KL, Bandmann O, Strong M. The prevalence of juvenile Huntington's Disease: a review of the literature and meta-analysis. PLoS Curr 2012. Doi: 10.1371/4f8606b742ef3

3 Cardoso F. Huntington disease and other choreas. Neurol Clin 2009;27(03):719-736

4 Gonzalez-Alegre P, Afifi AK. Clinical characteristics of childhoodonset (juvenile) Huntington disease: report of 12 patients and review of the literature. J Child Neurol 2006;21(03):223-229

5 Geevasinga N, Richards FH, Jones KJ, Ryan MM. Juvenile Huntington disease. J Paediatr Child Health 2006;42(09):552-554

6 Lee JM, Ramos EM, Lee JH, et al; PREDICT-HD study of the Huntington Study Group (HSG); REGISTRY study of the European Huntington's Disease Network; HD-MAPS Study Group; COHORT study of the HSG. CAG repeat expansion in Huntington disease determines age at onset in a fully dominant fashion. Neurology 2012;78(10):690-695

7 Trottier Y, Biancalana V, Mandel JL. Instability of CAG repeats in Huntington's disease: relation to parental transmission and age of onset. J Med Genet 1994;31(05):377-382

8 Langbehn DR, Hayden MR, Paulsen JS; and the PREDICT-HD Investigators of the Huntington Study Group. CAG-repeat length and the age of onset in Huntington disease (HD): a review and validation study of statistical approaches. Am J Med Genet B Neuropsychiatr Genet 2010;153B(02):397-408 
30 Huntington's Disease: Westphal Variant Cote-Orozco et al.

9 Aziz NA, Jurgens CK, Landwehrmeyer GB, et al; EHDN Registry Study Group. Normal and mutant HTT interact to affect clinical severity and progression in Huntington disease. Neurology 2009; 73(16):1280-1285

10 Gusella JF, MacDonald ME, Lee JM. Genetic modifiers of Huntington's disease. Mov Disord 2014;29(11):1359-1365

11 Nance M, Myers R, Wexler A, Zanko A, United States Huntington's Disease Genetic Testing Group. Genetic testing for Huntington's disease: its relevance and implications [Internet]. Huntington's
Disease Society of America. 2003 Available at: http://hdsa.org/ wp-content/uploads/2015/03/GeneticTesting-for-HD.pdf. Accessed September 15, 2017

12 The Human Genetics Society of Australasia. Presymptomatic and predictive testing for genetic disorders [Internet]. 2014 Available at: https://www.hgsa.org.au/documents/item/1574. Accessed September 15, 2017

13 Toufexis M, Gieron-Korthals M. Early testing for Huntington disease in children: pros and cons. J Child Neurol 2010;25(04):482-484 